\title{
FRACTURE LOCUS OF A COR-TEN WEATHERING STEEL: EXPERIMENTAL-NUMERICAL CALIBRATION
}

\author{
F. CONCLI \& L. MACCIONI \\ Free University of Bolzano/Bozen, FaST, Bz, Italy.
}

\begin{abstract}
Cor-Ten is a weathering steel exploited in the last decade for several applications such as bridges, artworks, building facades, etc. Besides a good strength, it naturally oxides creating a protective layer. This oxide, unlike rust, has the same specific volume of the pure metal. This characteristic allows overcoming the need of protecting treatments like galvanization, etc.

While its properties promote its exploitation in civil applications, there are also some examples of application where safety is a fundamental requirement. In the northern part of Italy, Cor-Ten is used for safety barriers (guard rails) along the highways. It is, therefore, fundamental to know the ductile behavior of this material, for which few data are available in literature.

Quasi-static experimental tensile tests have been performed on eight samples having different shapes. Numerical simulations carried out with an open-source code (Code_Aster) reproduced the experimental setup. In this way, it was possible to calculate the stress state and the plastic strain at failure needed for the calibration of the ductile damage model. The material model is based on classical incremental plastic response with isotropic hardening and phenomenological concept of damage.

Keywords: Code_Aster, Cor-Ten, ductile fracture, experiments, FEM, fracture locus.
\end{abstract}

\section{INTRODUCTION}

In the 30s, 'U.S. Steels' developed a new material (weathering steel) with self-passivating properties. Its chemical composition consisted of, besides $\mathrm{Fr}, \mathrm{Cu}, \mathrm{Cr}$, and $\mathrm{P}$ [1]. To highlight the outstanding resistance to CORrosion and TENsion, the new material was precisely called Cor-Ten. In the following years, its initial chemical composition underwent some minor adjustments [2]. Its mechanical properties were not the main reason of its exploitation and interest in research. Indeed, its passivating characteristics and resistance to corrosion inspired engineers, architects, and in the last years, artists to use this material. Cor-Ten was initially used mainly in the railway sector [3] to limit the corrosion of railway carriages. It was also used in bridges [4] to overcome the need of painting and maintenance. Only in the last decade, it started to be used for esthetic reasons also in facades [5] and several artworks [6].

Many researches focused on its wear behavior [7-9]. To create a protective layer, Cor-Ten requires special conditions, i.e. dry/wet alternation [10]. $\mathrm{Cl}^{-}$[11] and $\mathrm{SO}_{2}$ [12] negatively affect this phenomenon, especially in polluted environments. Furthermore, resistance to corrosion was investigated in the presence of different alloy elements [13], metal microstructures [14], and surface roughness [15].

Most of the South Tyrolean guard rails along the Brenner Highway [16], as well as minor roads are made of weathering steel. Its characteristic brown color ensures a low visual impact (Fig. 1) that is a fundamental aspect in a UNESCO world heritage environment as this mountain region.

Experimental tests were conducted to homologate the Cor-Ten guard rail installations [17, 18], but it is still essential to fine-tune the fracture locus through numerical FEM simulations and experiments to assert the safety performance of Cor-Ten guard rails [19]. Eventually, the tuned fracture locus could be exploited for traffic accident reconstructions. Since the main 


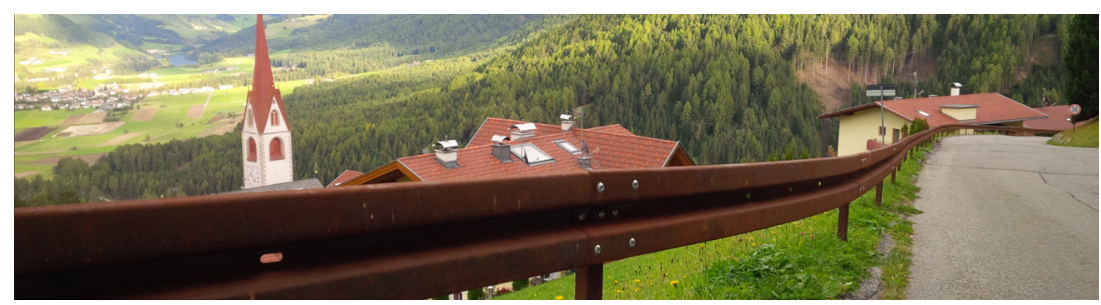

Figure 1: Example of Cor-Ten safety barrier. (http://www.metalwood.it/it/corten/)

function of safety barriers is 'to absorb energy during an impact' [20], it is fundamental for the characterization of the Cor-Ten plastic and fracture behavior.

\section{MATERIALS AND METHODS}

In this study, two series of samples made of Cor-Ten weathering steel were manufactured and tested $[21,22]$. The first series of samples was cut out from an 8-mm-thick sheet metal. The other series was cut from a 2-mm-thick one. The behavior of the material was characterized by means of traction tests performed on an MTS Criterion 45 testing machine (capable of applying loads up to $100 \mathrm{kN}$ ) available in the labs of unibz.

The constitutive law (stress-strain relation) was determined separately for the two series of samples (corresponding to two different sheet metal thicknesses), although significant differences were not observed. Additional tensile tests were performed on four different geometries for each thickness (Figs. 2 and 3). During the experiments, force, crosshead displacement, and axial deformation (measured with an extensometer) were measured.

Tests were performed with a crosshead speed of $0.1 \mathrm{~mm} / \mathrm{min}$ to avoid overheating of the samples that can affect the mechanical response.

While the first part of the $\sigma-\varepsilon$ curve (elastic region) can be directly derived from the measures, in the plastic (hardening) region, an inverse numerical procedure is required (especially once necking starts). Each test was reproduced numerically. The constitutive law was

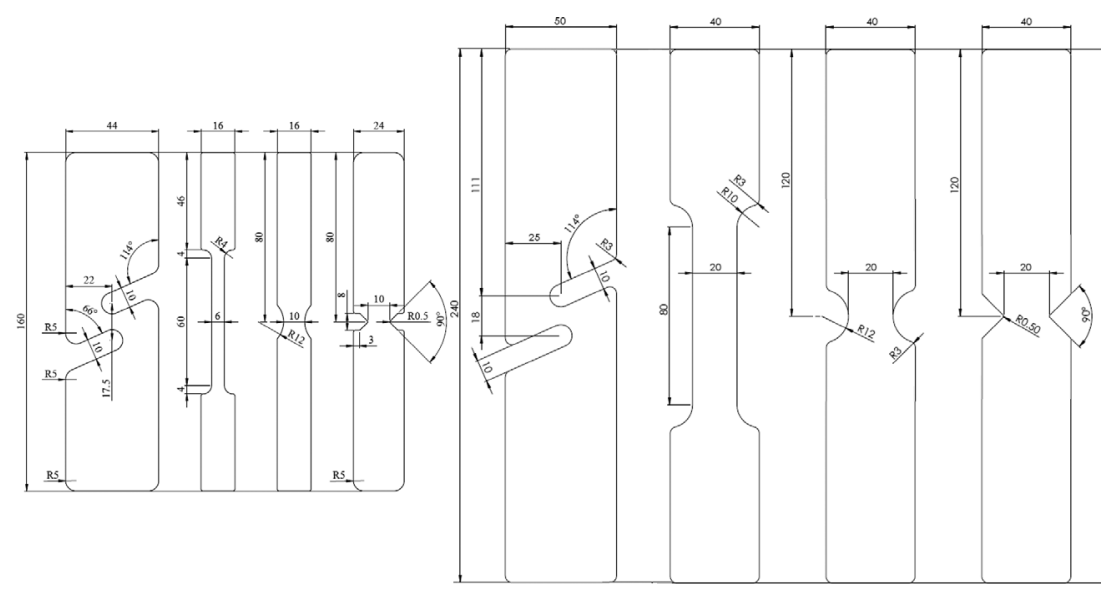

Figure 2: Sample geometries - from left: \#1.1, \#2.1, \#3.1, \#4.1, \#1.2, \#2.2, \#3.2, \#4.2 (the first number represents the series - 1 for 8-mm thickness, 2 for 2-mm thickness; the second number represents the geometry -1 for shear samples, 2 for smooth samples, 3 for round-notched samples, 4 for V-notched samples). 

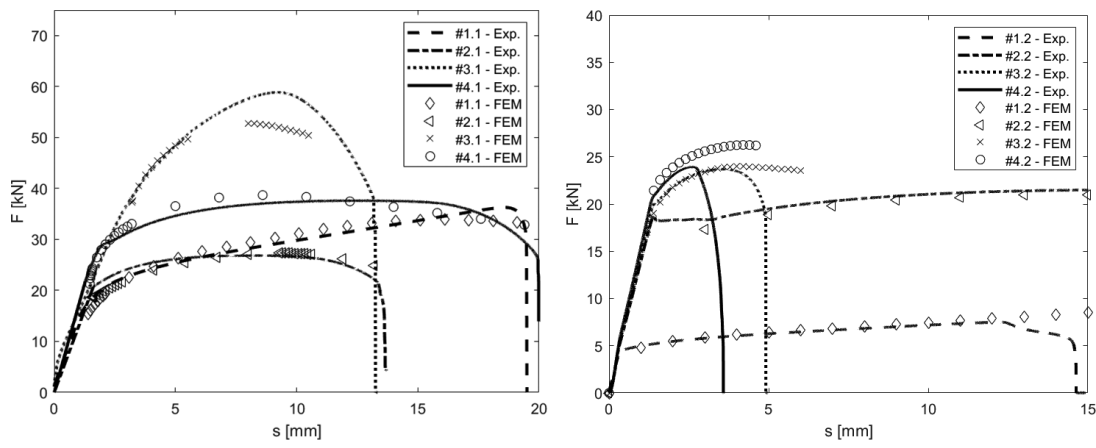

Figure 3: Force-displacement diagram - numerical vs. experimental. Left: geometries \#X.1; right: geometries \#X.2.

tuned iteratively by comparing the F-s (force-crosshead displacement) measurements with the equivalent numerical predictions.

The two sample groups that differ in terms of rolling process seem to have similar mechanical properties. Accordingly, the constitutive law can be described for both cases with the Voce law [23, 24]:

$$
\sigma=C_{1}+C_{2}\left(1-e^{-C_{3} \varepsilon_{p}}\right)+C_{4} \varepsilon_{p}
$$

where the constants $C_{i}$ are the yielding stress, the linear coefficient, the exponential coefficient, and the so-called exponential saturation parameter, respectively, and $\varepsilon_{P}$ is the accumulated plastic strain (Table 1).

For further validation, the stress fields obtained with the tuned numerical models were compared with 2D Digital Image Correlation (DIC) measurements. A single camera (reflex Nikon D750 with a $24-85$ zoom and a stabilizer) was used to acquire pictures of the sample each second. An external light source was used to ensure proper illumination of the specimen surface.

2D DIC is an advanced optical measurement technique that allows to reconstruct displacement and strain fields of a planar component. The technology is based on the greyscale; before the tests, the samples should be painted with a black and white "speckle" pattern. The camera should be positioned perpendicularly to the specimen surface. The first picture acquired (undeformed sample) is used as reference. A post-processing algorithm creates a virtual grid on the image of the specimen's surface dividing the total area into several smallest facets. Cross-correlation operations allow the recognition of facets across all the time steps. Once all subsets are recognized for each time step, the algorithm reconstructs the displacement, and eventually the strain-field of the tested specimen. The software used was GOM correlate. The comparison between DIC and FEM results fully validates the tuned Voce parameters; the discrepancies in terms of local stresses are below $5 \%$.

Table 1: Parameters of the Voce law for the Cor-Ten steel.

\begin{tabular}{llll}
\hline$C_{1}$ & $C_{2}$ & $C_{3}$ & $C_{4}$ \\
$(\mathrm{MPa})$ & $(\mathrm{MPa})$ & $(-)$ & $(\mathrm{MPa})$ \\
\hline 390 & 250 & 11 & 200 \\
\hline
\end{tabular}


In the years, several ductile damage models have been proposed. Mirza et al. [25] proposed one of the first models that relates stress triaxiality with the failure of metals. They used copper specimens. Additional models were developed by Rice \& Tracey [26], Hancock \& Mackenzie [27], and Johnson \& Cook [28]. All these models present a relation between the plastic strain at fracture $\varepsilon_{\text {peeq }}$ and the stress triaxiality $\eta$.

Triaxiality is a parameter representing the state of stress in the material. It is defined as:

$$
\eta=\frac{\sum \frac{\sigma_{i}}{3}}{\sqrt{\frac{1}{2}\left[\sum\left(\sigma_{i}-\sigma_{j}\right)^{2}\right]}}
$$

The model by Rice \& Tracey [26] is basically an exponential (decreasing) function. Hancock \& Mackenzie [27] and, successively, Johnson \& Cook [28], starting from the work of Rice \& Tracey, proposed new models that included the effects of temperature and strain rate also. Studies by Bao [29, 30], carried out on aluminum, showed how triaxiality affects the maximum plastic strain to fracture. This relation cannot be modeled with a monotonic decreasing function: different triaxiality levels are, for most of the materials, associated with different failure mechanisms (Fig. 4).

The fracture locus (Fig. 4) can be subdivided into three main regions along the abscissa (triaxiality level). For a low triaxiality, the failure mechanism is due to shearing; for a high triaxiality, the fracture is due to the nucleation-growth-coalescence mechanism. Between the two extremes, the fracture originates due to a combination of these mechanisms.

In this work, intermediate levels of triaxialities were considered. Additional investigations were planned in order to assess the $\eta-\varepsilon_{\text {peeq }}$ relation also for higher and lower triaxialities. Effects of temperature and strain rate were neglected.

The geometries of the samples used for tuning the ductile fracture model are shown in Fig. 2. The tensile tests were performed up to the rupture. The same configurations were

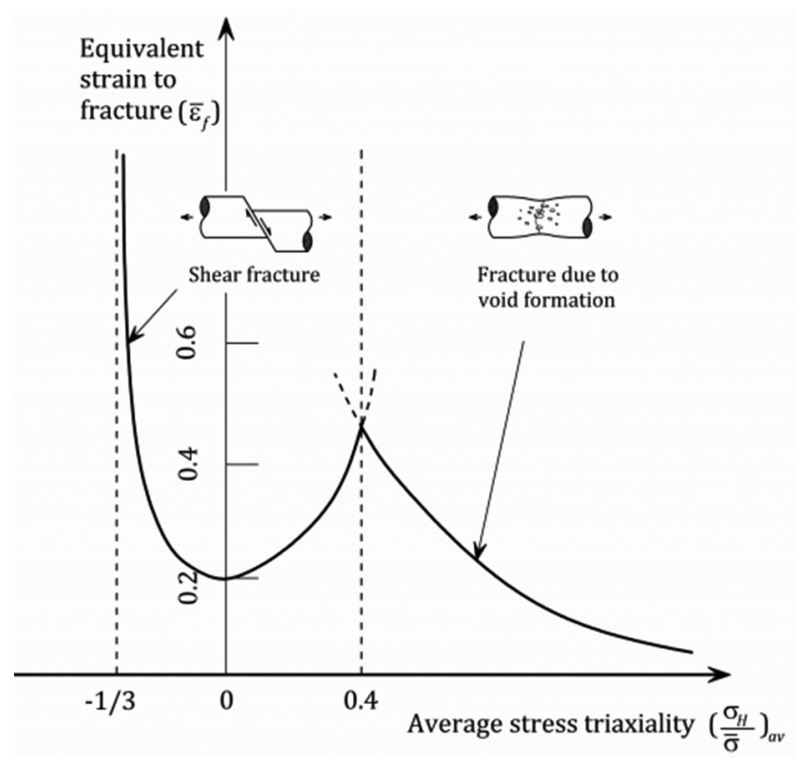

Figure 4: Relation between the stress triaxiality and the equivalent strain to fracture. Adapted from [30]. 
reproduced numerically [31-33] with the open-source free software Code-Aster. When it was possible, the numerical models were simplified, taking advantage of the symmetries. Opensource software allows the computation to be highly parallelized due to the absence of license limitations. Simulations were performed with an implicit non-linear solver. Simulations were stopped at the (crosshead) displacement that experimentally corresponds to the failure (Figs 5-8). From the simulations, the values of equivalent plastic strain at fracture $\varepsilon_{\text {peeq }}$ and the triaxiality $\eta$ (in the position that experimentally cracks) were extracted (Fig. 9). The values are reported in Table 2.

The fracture locus can be described by the equation (Fig. 8):

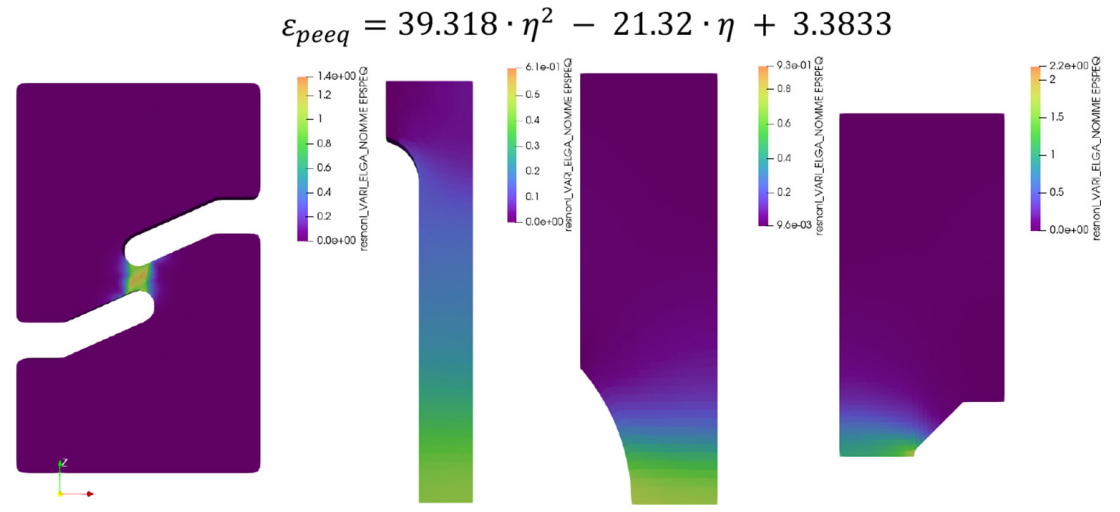

Figure 5: $\varepsilon_{\text {peeq }}$, sample \#1.1, \#2.1,\#3.1, and \#4.1.
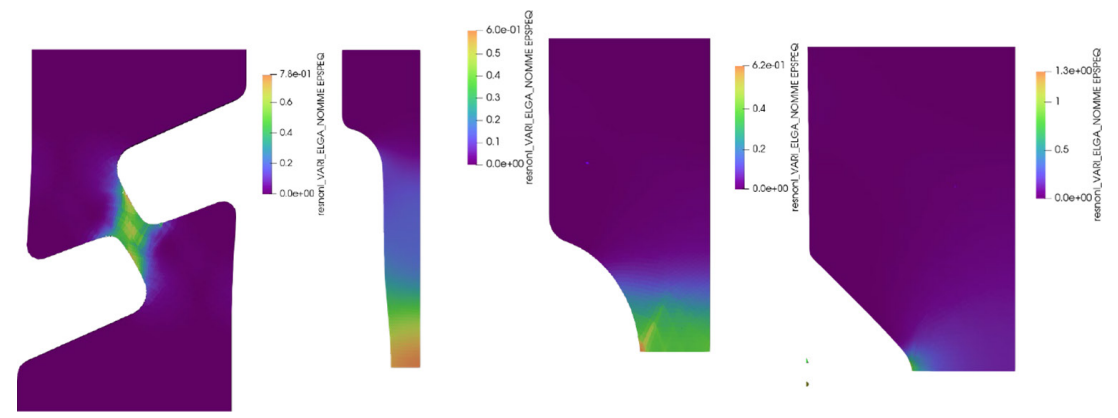

Figure 6: $\varepsilon_{\text {peeq }}$, sample \#1.2, \#2.2,\#3.2, and \#4.2.
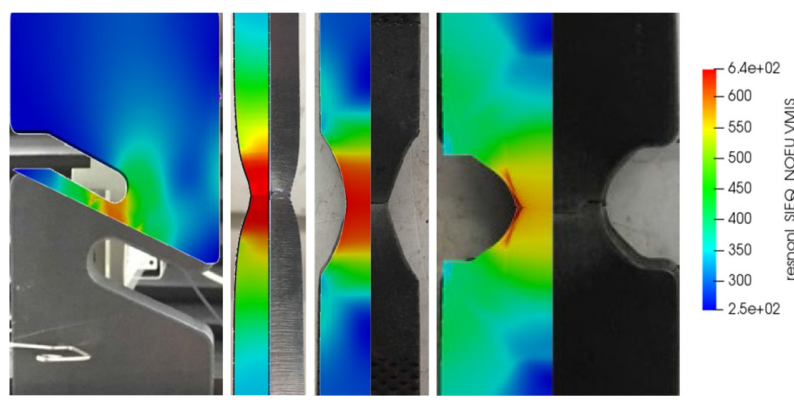

Figure 7: Numerical results overlapping the real samples: from left geometries \#1.1, \#2.1, \#3.1, and \#4.1 (vM stress). 

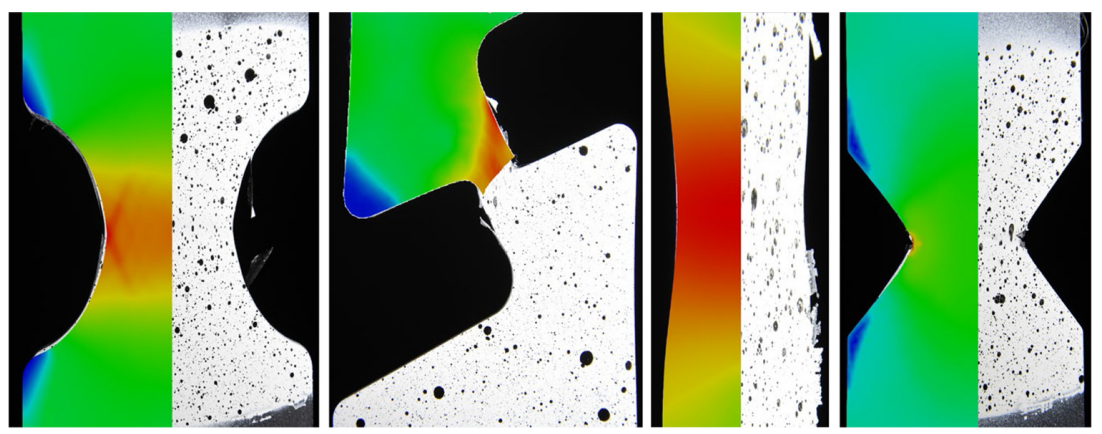

Figure 8: Numerical results overlapping the real samples: from left geometries \#1.2, \#2.2, \#3.2, and \#4.2 (vM stress).

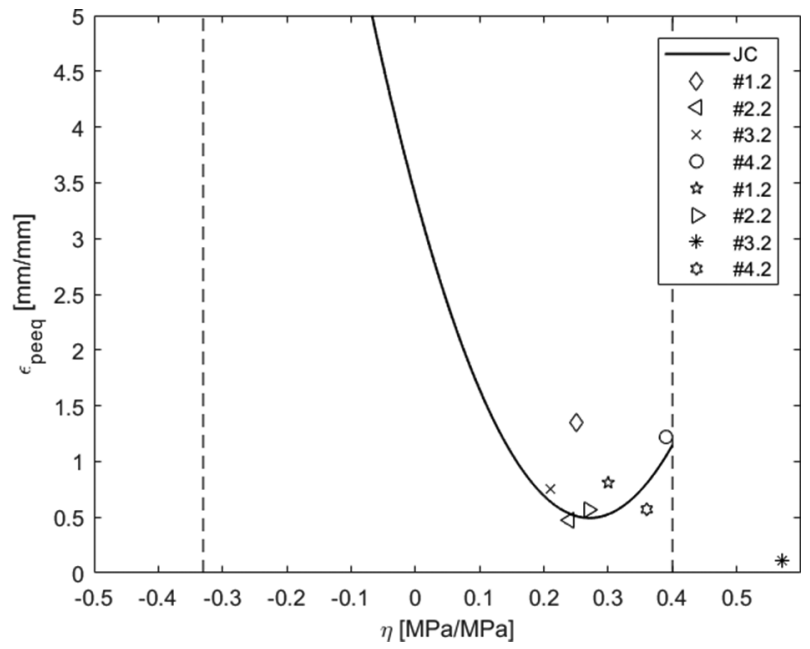

Figure 9: Fracture locus.

Table 2: Triaxiality $\eta$ and equivalent plastic strain at fracture.

\begin{tabular}{lllllllll}
\hline \multicolumn{8}{c}{ Sample geometry } \\
\hline & $\# 1.1$ & $\# 2.1$ & $\# 3.1$ & $\# 4.1$ & $\# 1.2$ & $\# 2.2$ & $\# 3.2$ & $\# 4.2$ \\
& 0.25 & 0.23 & 0.21 & 0.39 & 0.30 & 0.27 & 0.55 & 0.36 \\
$\varepsilon_{\text {peeq }}$ & 1.35 & 0.47 & 0.75 & 1.22 & 0.81 & 0.57 & 0.11 & 0.57 \\
\hline
\end{tabular}

The interpolation of the seven points $\left(\varepsilon_{\text {peeq }}-\eta\right)$ failing in the medium-range triaxiality leads to the fracture locus shown in Fig. 9. The shear sample \#3.2 fails likely due to void formation () and is out of the scope of this paper.

The interpolation curve is

$$
\varepsilon_{\text {peeq }}=39.318 \cdot \eta^{2}-21.32 \cdot \eta+3.3833
$$




\section{CONCLUSIONS}

In this work, the Johnson \& Cook ductile fracture model was calibrated for a Cor-Ten weathering steel. The effects of strain rate and temperature were neglected, but will be included in future studies.

Once the constitutive law was obtained with an iterative procedure, calibration of the fracture locus was performed. While eight tests were performed on samples with different geometries and thicknesses, only the results of seven of them were used for the calibration of the fracture locus in the mid-triaxiality region, where the fracture originates due to a combination of different mechanisms. One sample, in fact, shows a value of triaxiality higher than 0.4, which is considered the threshold for the behavior transition (void formation - nucleation-growth-coalescence region).

The seven samples falling withing the triaxiality range of interest lie well on a second-order polynomial curve.

Future studies will complete the calibration of the fracture locus also for the shearing region and the nucleation-growth-coalescence region. Furthermore, the model will be used for the study of the behavior of a guard rail in Cor-Ten during an impact.

\section{ACKNOWLEDGEMENT}

The authors would like to thank AERRE [35] for the financial support.

\section{REFERENCES}

[1] Decker, P. et al., To coat or not to coat? The maintenance of Cor-Ten® sculptures. Material and Corrosion, 59(3), pp. 239-247, 2008. https://doi.org/10.1002/maco.200804099

[2] Revie, R. W., Uhlig's Corrosion Handbook: Third Edition. 2011.

[3] Dunkley, F. G., Painting of railway rolling stock. Journal of the Institution of Locomotive Engineers, 57(319), pp. 509-553, 1967. https://doi.org/10.1243/jile_ proc_1967_057_057_02_

[4] Fischer, M., Weathering Steel in Bridges. Structural Engineering International, 5(1), pp. 51-54, 1995. https://doi.org/10.2749/101686695780601547.

[5] Mostafavi, D. et al., On Weathering: The Life of Buildings in Time. Massaciussets Intitute of Technology, 1993.

[6] https://www.pinterest.it/trackdesign9867/corten+art/?lp=true

[7] Kamimura, T. et al., Composition and protective ability of rust layer formed on weathering steel exposed to various environments. Corrosion Science, 48(9), pp. 2799-2812, 2006. https://doi.org/10.1016/j.corsci.2005.10.004

[8] Morcillo, M. et al., Atmospheric corrosion data of weathering steels. A review. Corrosion Science, 77, pp. 6-24, 2013. https://doi.org/10.1016/j.corsci.2013.08.021

[9] Concli, F. et al., Load independent power losses of ordinary gears: Numerical and experimental analysis. in 5th WTC 2013, 2, 2013.

[10] RJ, S. et al., For Architectural Applications-Unpainted High Strength Low Alloy Steel. Matls Prot, 8(12), pp. 70-77, 1969.

[11] Zhang, Q. C. et al., Corrosion behavior of weathering steel in marine atmosphere. Materials Chemistry and Physics, 77(2), pp. 603-608, 2003. https://doi.org/10.1016/s02540584(02)00110-4

[12] Wang, J. H. et al., The corrosion mechanisms of carbon steel and weathering steel in SO2 polluted atmospheres. Materials Chemistry and Physics, 47(1), pp. 1-8, 1997. https://doi.org/10.1016/s0254-0584(97)80019-3 
[13] Wang, R. et al., Electrochemical corrosion performance of $\mathrm{Cr}$ and $\mathrm{Al}$ alloy steels using a J55 carbon steel as base alloy. Corrosion Science, 85, pp. 270-279, 2014. https://doi. org/10.1016/j.corsci.2014.04.023

[14] Guo, X. et al., Influence of carbon content and microstructure on corrosion behaviour of low alloy steels in a $\mathrm{Cl}$ - containing environment. Corrosion Science, 51(2), pp. 242-251, 2009. https://doi.org/10.1016/j.corsci.2008.10.025

[15] Chiavari, C. et al., Atmospheric corrosion of Cor-Ten steel with different surface finish: Accelerated ageing and metal release. Materials Chemistry and Physics, 136(2-3), pp. 477-486, 2012. https://doi.org/10.1016/j.matchemphys.2012.07.014

[16] https://www.autobrennero.it/documenti/4_Area_tecnica/Pubblicazioni/2010/barriere_ sicurezza_A22.pdf

[17] https://www.autobrennero.it/it/la-rete-autostradale/la-sicurezza/barriere-sicurezza/

[18] Deflorian, F. et al., Premature corrosion failure of structural highway components made from weathering steel. Engineering Failure Analysis, 9(5), pp. 541-551, 2002. https:// doi.org/10.1016/s1350-6307(01)00038-3

[19] Whitworth, H. A. et al., Finite element modeling of the crash performance of roadside barriers. International Journal of Crashworthiness, 9(1), pp. 35-43, 2004. https://doi. org/10.1533/ijcr.2004.0270

[20] Ren, Z. et al., Computational and experimental crash analysis of the road safety barrier. Eng. Fail. Anal., 12(6) SPEC. ISS., pp. 963-973, 2005. https://doi.org/10.1016/j. engfailanal.2004.12.033

[21] Concli, F. et al., Experimental-Numerical Calibration of The Fracture Locus of a Weathering Steel. WIT Transactions on Engineering Sciences, 2019.

[22] Concli, F. et al., Fracture locus of a CORTEN steel: Finite Element calibration based on experimental results. Procedia Structural Integrity, 2019.

[23] Voce, E., A practical strain-hardening function. Metallurgia, 51, pp. 219-226, 1955.

[24] Voce, E., The relationship between stress and strain for homogeneous deformation. $J$. Inst. Met., 74, pp. 537-562, 1948. https://doi.org/10.1201/b19173-7

[25] Mirza, M. S. et al., Ductile fracture of pure copper: An experimental and numerical study. Journal De Physique. IV : JP, 7(3), pp. C3-891-C3-896, 1997. https://doi. org/10.1051/jp4:19973150

[26] Rice, J. R. et al., On the ductile enlargement of voids in triaxial stress fields*. J. Journal of the Mechanics and Physics of Solids, 17(3), pp. 201-217, 1969. https://doi. org/10.1016/0022-5096(69)90033-7

[27] Hancock, J. W. et al., On the mechanisms of ductile failure in high-strength steels subjected to multi-axial stress-states. Journal of the Mechanics and Physics of Solids, 24(2-3), pp. 147-160, 1976. https://doi.org/10.1016/0022-5096(76)90024-7

[28] Johnson, G. R. et al., A constitutive model and data for metals subjected to large strains, high strain rates and high temperatures. A Const. Model Data Met. Subj. to Large Strains, High Strain Rates High Temp, pp. 541-547, 1983.

[29] Bao et al., On fracture locus in the equivalent strain and stress triaxiality space. International Journal of Mechanical Sciences, 46(1), pp. 81-98, 2004. https://doi.org/10.1016/j. ijmecsci.2004.02.006

[30] Suárez, F. et al., Distinct fracture patterns in construction steels for reinforced concrete under quasistatic loading — A review. Metals, 8(3), 2018. 
[31] Concli, F. et al., Numerical and experimental assessment of the static behavior of $3 \mathrm{~d}$ printed reticular Al structures produced by Selective Laser Melting: progressive damage and failure. Procedia Structural Integrity, pp. 204-212, 2018.

[32] Concli, F. et al., Numerical and experimental assessment of the static behavior of 3D printed reticular Al structures produced by Selective Laser Melting: proressive damage and failure. Procedia Structural Integrity, pp. 204-212, 2018.

[33] Concli, F. et al., Experimental-numerical assessment of ductile failure of Additive Manufacturing selective laser melting reticular structures made of Al A357. Prooceding of the international. Journal of Mechanical Engineering Science - Part C, 2019.

[34] A.ERRE Srl di Serravalle Pistoiese (PT) Italy. http://www.aerrecarpenteria.it/ 